\title{
Ion Accumulation Time Dependent Molecular Characterization of Natural Organic Matter Using Electrospray lonization-Fourier Transform Ion Cyclotron Resonance Mass Spectrometry
}

\author{
Dong Cao, ${ }^{\circledR}$ Jitao Lv, Fanglan Geng, Ziyu Rao, Hongyun Niu, Yali Shi, Yaqi Cai, and Yuehui Kang*
}

State Key Laboratory of Environmental Chemistry and Ecotoxicology, Research Center for Eco-Environmental Science, Chinese Academy of Sciences, P.O. Box 2871, 18 Shuangqing Road, Haidian district, Beijing 100085, China

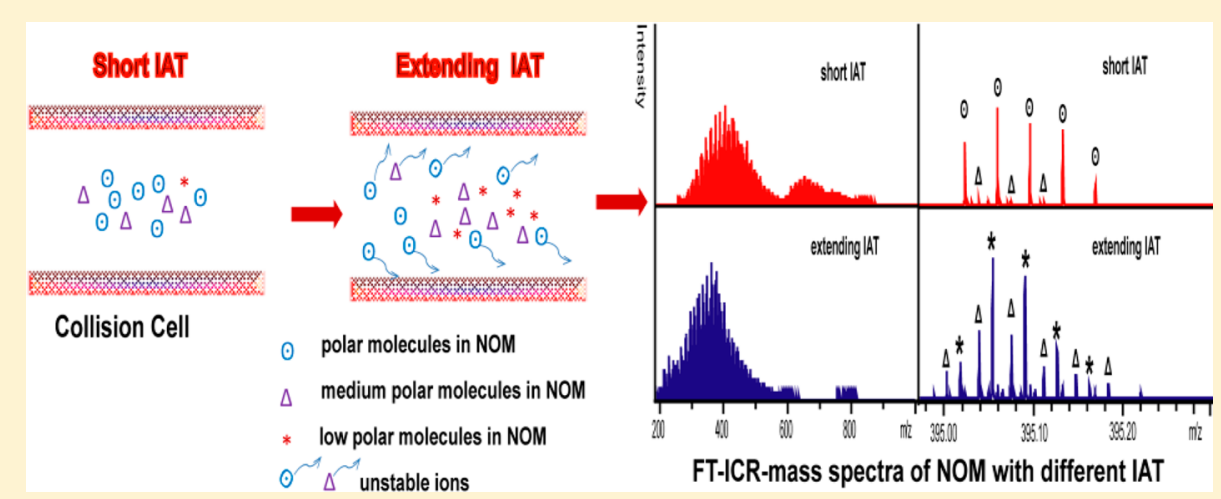

ABSTRACT: Natural organic matter (NOM) is a complex organic mixture and plays a crucial role in environmental processes. By using Fourier transform ion cyclotron resonance mass spectrometry (FTICR-MS), detailed molecular information on NOM could be achieved. In this paper, ion accumulation time (IAT), a key parameter of FTICR-MS for complex mixture detection, was the focus, and its effect on the molecular characterization of NOM by FTICR-MS was systematically investigated. A notable feature of selective detection of NOM molecules by FTICR-MS with different IAT was observed. Most of the polar molecules with high $\mathrm{O} / \mathrm{C}$ ratio $(\mathrm{O} / \mathrm{C}$ ratio $>0.5)$ could be easily detected by FTICR-MS with a short IAT, but extending IAT led to the ion intensities of these molecules decreasing or even disappearing. Meanwhile, a large number of unsaturated and aromatic molecules with low $\mathrm{O} / \mathrm{C}$ ratio $(\mathrm{O} / \mathrm{C}$ ratio $<0.6)$ and low polarity, all of which could not be observed with a short IAT, were remarkably detected by extending IAT. Results also revealed that the unsaturated and aromatic molecules, which could only be observed by extending the IAT, were not generated by the fragmentation of molecules in NOM or from the dissociation of NOM aggregations but originally existed in NOM samples. The selective detection of NOM molecules caused by IAT extension was possibly attributed to their different polarity and different stability in the collision cell. On the basis of these results, a novel strategy of combining mass spectrometric data of NOM obtained with different IAT by FTICR-MS was proposed. With this strategy, more than 4715 CHO-molecular formulas were assigned, where about 2000 more formulas were obtained in comparison with using a short IAT (2733 CHO-molecular formulas identified) solely. The strategy is simple and robust and can be used as an alternative method to obtain more molecular information on NOM in the environment.

$\mathrm{N}$ atural organic matter (NOM) is a very complicated heterogeneous mixture and exists widely in the environment. These natural organic constituents have significant effect on the global carbon cycle, ${ }^{1}$ transport processes of pollutants, ${ }^{2}$ bioavailability of heavy metals, ${ }^{3}$ and the quality of water during chlorine treatment. ${ }^{4,5}$ However, the key to greater understanding of the effect of NOM on the environment is the achievement of the molecular composition and exact structure of NOM itself.

For molecular structure of NOM, early concepts supported the "polymer model" which proposed that NOM was composed of randomly coiled macromolecules. ${ }^{6,7}$ However, recently, more and more information gathered using spectroscopic, ${ }^{8,9}$ microscopic, ${ }^{10,11}$ and soft ionization ${ }^{12-14}$ techniques supported another concept named "supramolecular associa- tion", which believed that lots of relatively small and chemically diverse organic molecules in NOM are held together by weak interactions, such as hydrogen bonding, $\pi$-bonding, van der Waals forces, and hydrophobic forces, to form supramolecular aggregation. ${ }^{15-17}$ On the basis of this concept, many analytical techniques have been developed for separation and characterization of NOM molecules. ${ }^{18}$ In particular, Fourier transform ion cyclotron resonance mass spectrometry (FTICR-MS) in a high magnetic field, due to its ultrahigh mass resolving power and mass accuracy, has become one of the most important tools for accurate characterization of NOM at the molecular

Received: August 16, 2016

Accepted: November 28, 2016

Published: November 28, 2016 
level. ${ }^{19-21}$ Thousands of empirical formulas of small individual NOM components (which typically range from 200 to $700 \mathrm{Da}$ ) could be calculated through their corresponding $\mathrm{m} / z$ values accurately detected by FTICR-MS. ${ }^{22}$ Furthermore, on the basis of these molecular formulas, diagrams could be created to categorize the NOM components into different compound classes, such as lipids, lignin, tannins, and condensed aromatics. Subsequently, hydrophobicity, aromaticity, and the degree of unsaturation of these NOM components could be evaluated. $^{23-26}$

While FTICR-MS could provide molecular information on NOM, comprehensive characterization of NOM molecules by this single technique could not be achieved due to the complexity of NOM. Therefore, multiple separation techniques and ionization techniques were combined with FTICR-MS in order to obtain more molecular information on NOM. For example, size-exclusion chromatography (SEC), ${ }^{27-29}$ reversedphase high performance liquid chromatography (RPHPLC), ${ }^{30-33}$ and the solvent-based extraction method ${ }^{34}$ were all developed to separate NOM components into several fractions based on their different physical-chemical properties, followed by detection with FTICR-MS. Since the degree of complexity of NOM was reduced by separation or extraction, more individual NOM components could be detected by FTICR-MS. On the other hand, different ion sources, such as electrospray ionization (ESI), ${ }^{35}$ atmospheric chemical ionization (APCI), ${ }^{20}$ atmospheric pressure photoionization (APPI), ${ }^{36}$ and matrix assisted laser desorption/ionization (MALDI), ${ }^{37}$ show biases toward certain classes of compounds. The results reported by Hertkorn et al. ${ }^{20}$ indicated that small and oxygendeficient molecules were preferentially ionized in the negative APCI mode, but oxygen-rich molecules were preferentially ionized in the negative ESI and APPI mode. Recently, our published results showed that carbon-rich, oxygen-deficient ( $\mathrm{O} / \mathrm{C}$ ratio $<0.5)$, more unsaturated, and aromatic constituents of NOM were preferentially ionized in MALDI negative mode. ${ }^{37}$ Thus, in order to obtain comprehensive molecular information about NOM, multiple ionization methods should be combined.

Although there had been much research on NOM investigated by FTICR-MS, we found that ion accumulation time (IAT), a key parameter for complex mixture detection using FTICR-MS, was not paid much attention. Different IAT values ranging from several hundred milliseconds to a few tens of seconds were set by different groups in previous studies. $^{20,25,38,39}$ IAT is the time of ions accumulating in the collision cell before entering the FTICR cell. A rational IAT extension would increase the number of ions accumulated in the collision cell and, subsequently, enhance ions intensity and sensitivity. ${ }^{40}$ However, over extension of IAT would cause an adverse impact on the detection of analytes. Smith and coworkers had reported that pronounced $\mathrm{m} / z$ discrimination was observed by changing the accumulation of peptide ions in a quadrupole interface external to the FTICR cell. ${ }^{41}$ Moreover, remarkable dissociation occurred after extending the accumulation time. ${ }^{42}$ More interestingly, Da Campo et al. reported that singly charged noncovalent dimers of naphthenic acids were observed using FTICR-MS; however, the lifetime of these dimer ions is significantly affected by the accumulation time within the hexapole ion trap. This behavior is attributed to the dissociation of these dimers through noncovalent bond destruction since a longer residence time inside the hexapole would cause an increase in the number of collisions. ${ }^{43}$ On the basis of the previous reports and the complexity of NOM, different IATs may have influence on the molecular characterization of NOM by FTICR-MS. However, to the best of our knowledge, until now, there are no studies that paid much attention to this topic.

The aim of this work is to focus on the effect of IAT on the molecular characterization of NOM by FTICR-MS. A systematically molecular visual comparison of mass spectra generated with different IAT was performed. Possible mechanisms to explain the effect of IAT on the NOM detection by FTICR-MS were proposed. A novel strategy of combining mass spectrometric data of NOM obtained with different IAT was proposed to obtain more molecular information on NOM.

\section{EXPERIMENTAL SECTION}

Chemicals and Samples Preparation. Suwannee river natural organic matter (SuwNOM) was purchased from the International Humic Substances Society. Ultrapure water was prepared using a Milli-Q system (Millipore, Milford, MA, USA). Acetonitile (ACN) and methanol (HPLC grade) were purchased from Fisher Scientific (Fair Lawn, N.J., USA). Other chemicals were analytical grade. $0.1 \mathrm{mg} \mathrm{mL}^{-1}$ of NOM solution was prepared by dissolving $\mathrm{NOM}$ in $50 \% \mathrm{ACN}$ aqueous solution; for ESI-FTICR-MS analysis, $0.1 \mathrm{mg} \mathrm{mL}^{-1}$ of NOM in $50 \% \mathrm{ACN}$ solution was directly infused into the ESI source unit at a flow rate of $120 \mu \mathrm{L} \mathrm{h}^{-1}$.

Instrumentation. Ultrahigh resolution mass spectra were acquired using a Bruker Solarix Fourier transform ion cyclotron resonance (FTICR) mass spectrometer (Bruker Daltonik, $\mathrm{GmbH}$, Bremen, Germany) equipped with a $15.0 \mathrm{~T}$ superconducting magnet and a dual-mode ESI/MALDI ion source. For ESI analysis, samples were continuously infused into the ESI unit by syringe infusion at a flow rate of $120 \mu \mathrm{L} \mathrm{h}^{-1}$. ESI needle voltage was set to $4.0 \mathrm{kV}$. All samples were analyzed in negative ionization mode with broadband detection. Ions were accumulated in a hexapole collision cell for different times according to the experiment before being introduced into the ICR cell. $4 \mathrm{M}$ 32-bit data points were recorded per broadband mass scan. The lower mass limit was set to $m / z=185 \mathrm{Da}$, and the upper mass limit was set to $m / z=1000 \mathrm{Da}$. 200 scans were averaged per spectrum. An average resolving power $\left(\mathrm{m} / \Delta \mathrm{m}_{50 \%}\right)$ of over 400000 at $m / z \sim 400$ was achieved. The spectra were externally calibrated on the basis of clusters of sodium formate $(10 \mathrm{mM})$ in $50 \%$ isopropyl alcohol and then internally recalibrated using an in-house reference mass list. After internal calibration, the mass error was less than $500 \mathrm{ppb}$ over the entire mass range. The mass measurement error histogram of 55 matched reference masses was shown in Figure 1. Peaks were identified with Bruker Data Analysis software.

For collision-induced dissociation in quadrupole (q-CID), the precursor ions were selected in the quadrupole with isolation window of 2 masses units, and then, the selected precursor ions were accumulated with an IAT of $6 \mathrm{~s}$ and fragmented in the collision cell. For continuous accumulation of selected ions (CASI), the ions of interest were first isolated with an isolation window of 5 units by the quadrupole mass filter and then accumulated in the collision cell for $10 \mathrm{~s}$. After continuous storage in the collision cell, the number of ions could be increased, and these ions could subsequently be transferred to the ICR cell for detection.

For MALDI analysis, 1,8-bis(dimethylamino)-naphthalene (DMAN) was used as the matrix. DMAN was dissolved in $100 \% \mathrm{ACN}$ to form $1 \mathrm{mg} \mathrm{mL}^{-1}$ of matrix solution. $0.5 \mathrm{mg} \mathrm{mL}^{-1}$ 


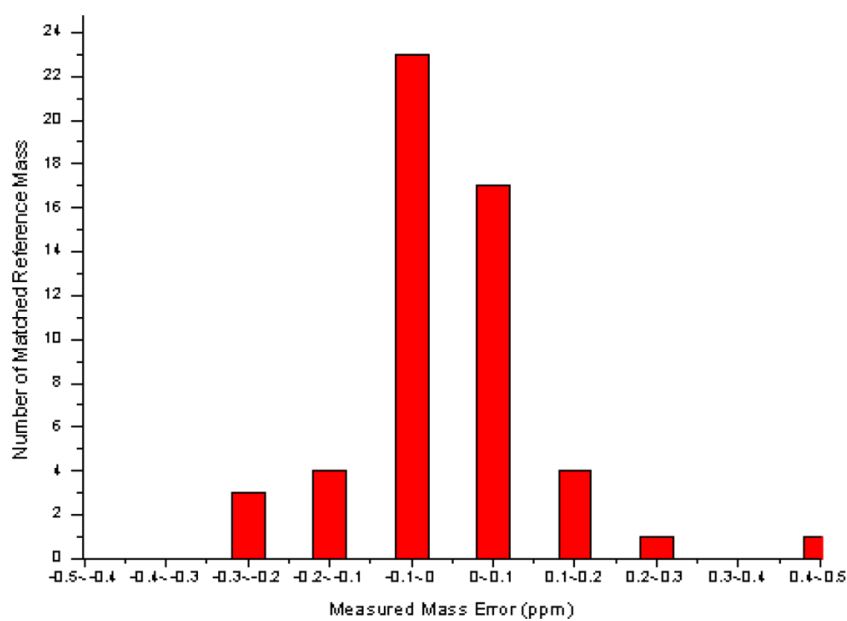

Figure 1. Mass measurement error histogram of all matched reference masses after internal calibration.

of NOM in 50\% ACN aqueous solution was mixed with $1 \mathrm{mg}$ $\mathrm{mL}^{-1}$ of DMAN matrix at equal volumes, and then, $1 \mu \mathrm{L}$ of the final solution was directly spotted on a 384-well MALDI target plate, followed by drying at room temperature for MALDIFTICR-MS analysis. A $355 \mathrm{~nm}$ and $1000 \mathrm{~Hz}$ solid-state Smartbeam Nd:YAG UV laser was used to irradiate the samples spotted on the target plate. Laser power was set at 30\%, and laser frequency was set at $100 \mathrm{~Hz} .200$ laser shots were summed for each scan, and 200 scans were averaged per spectrum. All samples were analyzed in negative ionization mode with broadband detection.

Molecular Formula Assignment. All possible formulas were calculated with Formula Calculator software based on the requirement that the mass error between the measured mass and the calculated mass for a given chemical formula is less than $0.5 \mathrm{ppm}$, and the signal-to-noise ratio $(\mathrm{S} / \mathrm{N})$ of assigned peaks is above 5. Only $\mathrm{C}, \mathrm{H}$, and $\mathrm{O}$ elements were considered in the calculation: ${ }^{12} \mathrm{C}(1-100),{ }^{1} \mathrm{H}(1-200),{ }^{16} \mathrm{O}(0-50)$, and ${ }^{13} \mathrm{C}$ $(0-1)$. The elemental ratios of $\mathrm{H} / \mathrm{C}<2.0$ and $\mathrm{O} / \mathrm{C}<1.2$ were used as further restrictions for formula calculation. Once formulas had been assigned, the obtained mass lists were transformed into Excel format and divided into different categories for interpretation. For visual graphic displays of the mass spectral data, the following parameters were calculated according to the previous reports: ${ }^{37} \mathrm{H} / \mathrm{C}$ ratio, $\mathrm{O} / \mathrm{C}$ ratio, and parameters for constructing van Krevelen diagram; the modified aromaticity index (AI mod) was calculated to estimate the fraction of aromatic and condensed aromatic structures.

\section{RESULTS AND DISCUSSION}

IAT is an important parameter of FTICR-MS for complex mixture detection. However, for complicated NOM mixture, no studies have paid much attention to the effect of IAT on the molecular characterization of NOM by using FTICR-MS. In this work, we mainly focus on this topic. First, a standard NOM sample is dissolved in 50\% ACN aqueous solution and detected by FTICR-MS under identical experimental conditions except the changing IAT ranged from 0.08 to $2 \mathrm{~s}$. The results are shown in Figure 2. We found that the peaks detected by FTICR-MS with different IAT followed similar, approximate Gaussian distributions in mass spectra within the $\mathrm{m} / \mathrm{z}$ range from 200 to 700 (Figure 2A1,B1,C1,D1), which was a remarkable feature of FTICR mass spectra of NOM widely reported in previous studies. ${ }^{25,39}$ However, when mass spectra at each nominal $\mathrm{m} / \mathrm{z}$ are extended in scale and compared, it is surprising to show that there are three different series of peaks detected with different IAT at each nominal $\mathrm{m} / z$ ranging from 200 to 700 . For example, the mass spectra at nominal $\mathrm{m} / z 395$ are shown in Figure 2A2-D2 (“)", “ $\Delta$ ", and “*” denoted different series of peaks). It is shown that the first series of peaks (“ $\odot$ " denoted in Figure 2A2) could be observed as the most abundant peaks with IAT at $0.08 \mathrm{~s}$, but the intensities of these peaks decrease gradually or even disappear with an extension of the IAT ( 0.64 to $2 \mathrm{~s})$. The second series of peaks with low intensities (" $\Delta$ " denoted in Figure 2A2) observed with IAT at $0.08 \mathrm{~s}$ gradually increase their intensities by extending IAT up to $0.64 \mathrm{~s}$ (as shown in Figure 2B2), and then, the intensities decrease with longer IAT ( 1 to $2 \mathrm{~s}$, as shown in Figure 2C2-D2). The third series of peaks ("*" denoted in Figure $2 \mathrm{~B} 2$ ) could only be detected with the IAT extending to $0.64 \mathrm{~s}$ or more.

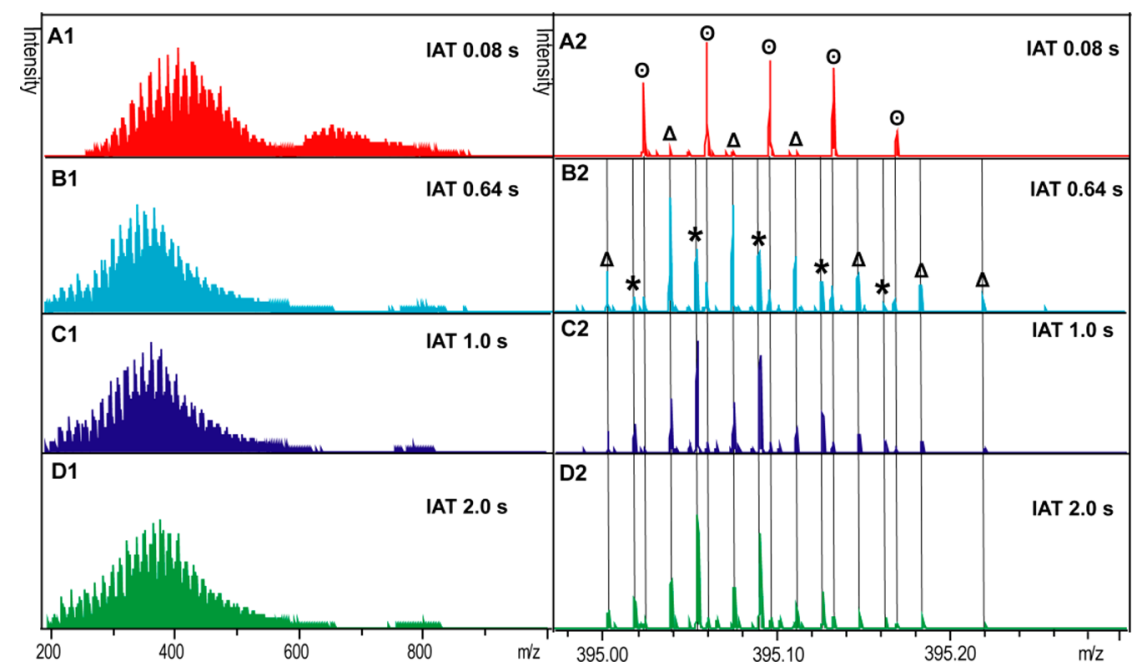

Figure 2. FTICR mass spectra of SuwNOM with IAT at $0.08 \mathrm{~s}$ (A1), $0.64 \mathrm{~s}$ (B1), $1 \mathrm{~s}(\mathrm{C} 1)$, and $2 \mathrm{~s}$ (D1); the scale-expanded $m / z$ segment at

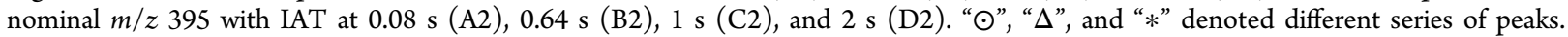




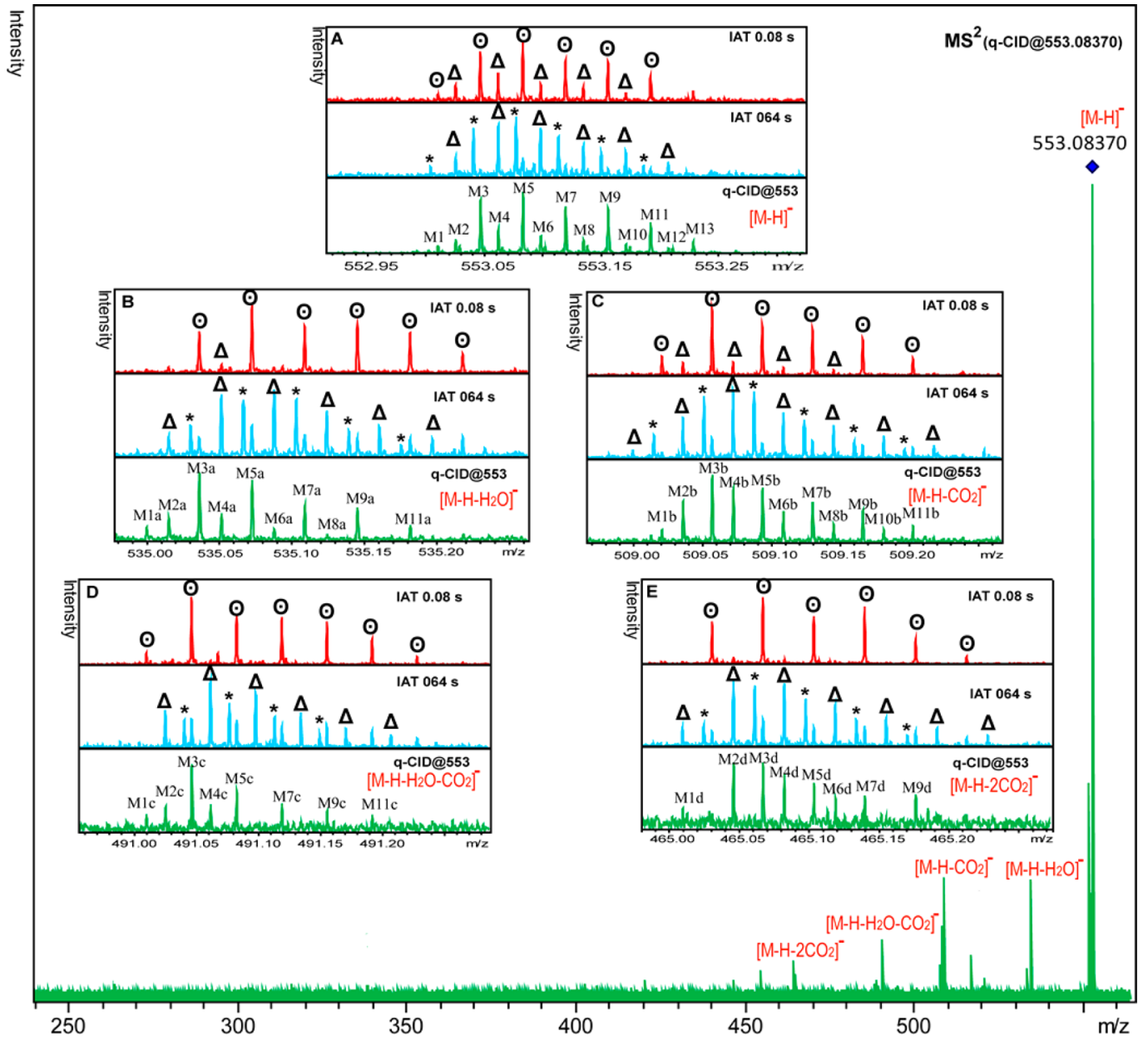

Figure 3. q-CID mass spectra at $m / z$ 553.08. The q-CID fragmentation spectra extended in scale at each nominal $\mathrm{m} / z$ of the fragmental ions and comparison with mass spectra obtained with IAT at 0.08 and $0.64 \mathrm{~s}$ (A to E). " $M_{n}$ " represents precursor ions; " $M_{n a}$ ", " $M_{n b}$ ", " $M_{n c}$ ", and " $M_{n d}$ " separately represents the fragment ions; “ $\odot$ ", “ $\Delta$ ", and “*” denoted different series of peaks.

For the first and the second series of peaks, it is reasonable that the intensities of these peaks change with an extension of IAT, because properly extending IAT could increase the number of ions accumulated in the hexapole, which leads to enhancement of the ions intensities. However, further extending IAT will reduce both the velocity and the kinetic energy of ions accumulated in the hexapole due to extended collisions with neutrals. ${ }^{44}$ Thus, loss of ions accumulated in the hexapole with longer IAT may occur.

However, for the third series of peaks, three possible pathways could be proposed to explain the generation of these peaks. One is that the third series of peaks may be produced by the fragmentation of molecules in NOM or dissociation of NOM aggregations formed by various molecules through noncovalent interaction. This possible pathway may be supported by several previous studies. For example, Hofstadler and co-workers reported that small proteins and peptides could be dissociated by extending ion accumulation interval. ${ }^{42} \mathrm{Da}$ Campo et al. reported that extending the IAT could partially destroy noncovalent interactions between dimers of naphthenic acids by an increase in the number of collisions in the hexapole. ${ }^{43}$ Since NOM contains a high functional group content including carboxylic, phenolic, ketonic, and polyaromatic moieties and could form supramolecular aggregation in aqueous solution by noncovalent interactions, ${ }^{15-17}$ fragmentation of molecules in NOM or dissociation of $\mathrm{NOM}$ aggregations may occur by extending IAT to form the third series of peaks. The second possible pathway is that the third series of peaks may be caused by space-charge frequency shifts of the first series of ions in NOM during MS detection. Because over extending IAT may lead ions to saturation in the accumulation hexapole, under this condition, the trapping efficiency of the hexapole may be greatly affected due to Coulombic collisions with the trapped ions. All of these may lead the space-charge frequency shifts of the first series of ions to form the third series of ions. The third possible pathway is that these peaks may be produced from the molecules originally existing in NOM but with low ionization efficiency or low concentration level. Such molecules could barely be detected in the mass spectra when a short IAT is used, because not enough ions are generated in the first place. However, extending IAT could efficiently increase the number of these ions accumulated in the collision cell, so that, the ion signals of these molecules could only be obtained with a longer IAT.

In order to demonstrate the first possible pathway, masses in the range between $\mathrm{m} / \mathrm{z} 300$ and 600 (because of their higher intensity in mass spectra) are selected as precursor ions (isolation window of 2 masses units) to perform collision induced dissociation (q-CID) in collision cell. One example of q-CID fragmentation spectra (at $m / z 553.0)$ is shown in Figure 3. The results show that no obvious ions formed by dissociation of NOM aggregations are observed. The fragment ions from 


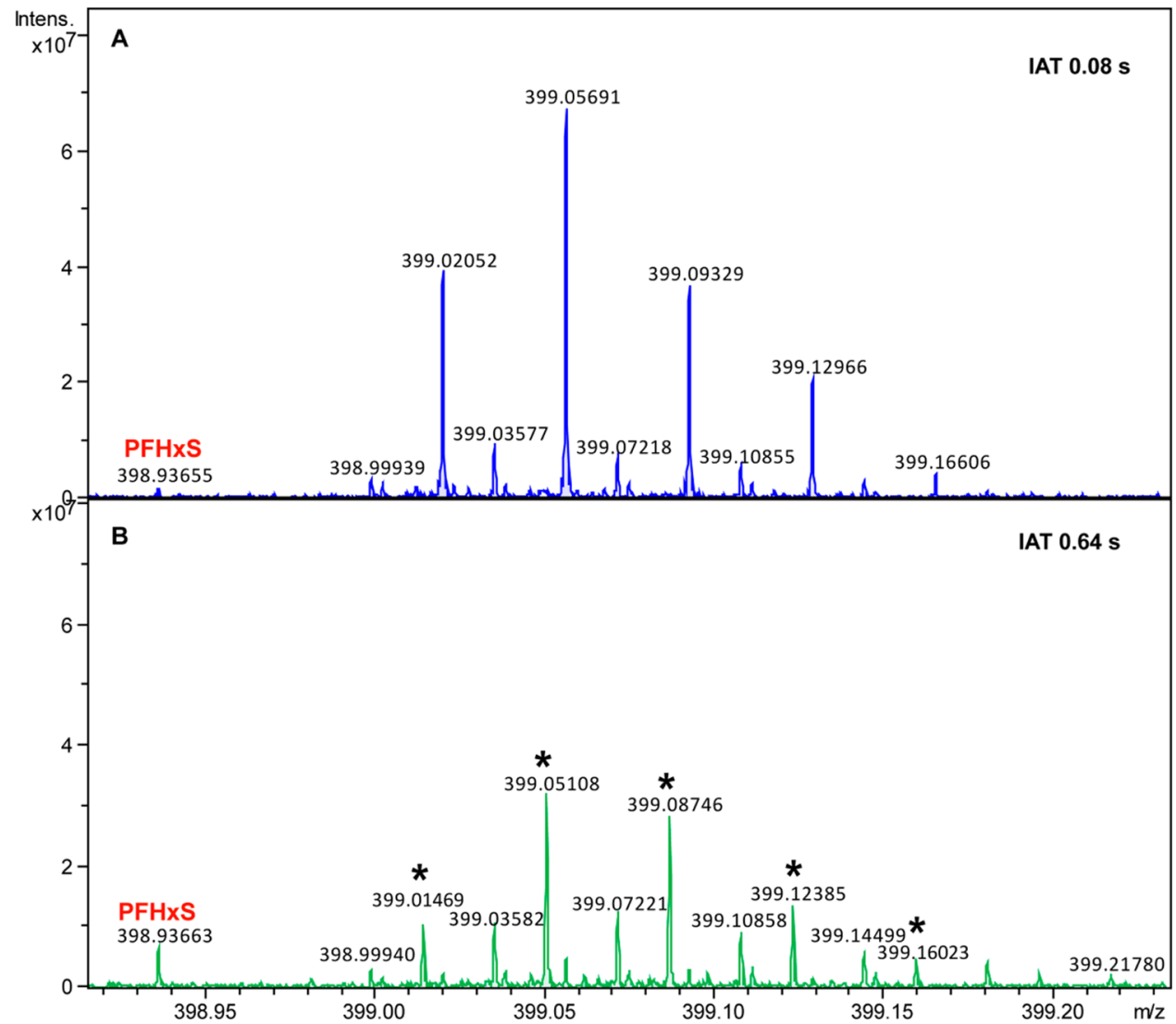

Figure 4. FTICR mass spectra of NOM mixed with PFHxS extended in scale at nominal $m / z 398$ to 399: (A) with IAT at $0.08 \mathrm{~s}$; (B) with IAT at $0.64 \mathrm{~s}$.

neutral losses of $\mathrm{CO}_{2}\left(\left[\mathrm{M}-\mathrm{H}-\mathrm{CO}_{2}\right]^{-}\right)$or $\mathrm{H}_{2} \mathrm{O}([\mathrm{M}-\mathrm{H}-$ $\mathrm{H}_{2} \mathrm{O}^{-}$) are observed with high intensities. Meanwhile, the successive loss of $\mathrm{CO}_{2}\left(\left[\mathrm{M}-\mathrm{H}-2 \mathrm{CO}_{2}\right]^{-}\right)$, the loss of $\mathrm{CO}_{2}$, and parallel loss of $\mathrm{H}_{2} \mathrm{O}\left(\left[\mathrm{M}-\mathrm{H}-\mathrm{CO}_{2}-\mathrm{H}_{2} \mathrm{O}\right]^{-}\right)$from precursor ions are also observed. These fragmentation patterns are in agreement with previous fragmentation studies. ${ }^{12,45}$ The q-CID fragmentation spectra are extended in scale at each nominal $\mathrm{m} /$ $z$ of these fragmental ions and are compared with mass spectra obtained with IAT at 0.08 and $0.64 \mathrm{~s}$ (as shown in Figure 3AE). Unfortunately, the third series of peaks ("*” denoted in Figure 3) only observed with the extension of IAT to $0.64 \mathrm{~s}$ or more are not detected in any MS/MS spectra. Nearly all of the q-CID fragmentation spectra at $\mathrm{m} / z$ ranging from 300 to 600 (the data were not shown) show similar fragment patterns, and the third series of peaks are not observed in these fragmentation spectra. These results support direct evidence to demonstrate that the third series of peaks are not produced by the fragmentation of molecules in NOM or dissociation of NOM aggregations.

In order to demonstrate the second possible pathway, perfluorohexyl sulfonate (PFHxS, $m / z=398.93661$ ), a stable standard compound, is added to $1 \mathrm{~mL}$ of NOM solutions ( 0.1 $\mathrm{mg} \mathrm{mL} \mathrm{m}^{-1}$ of NOM contained $100 \mathrm{ppt}$ of PFHxS); then, the final solution is detected by FTICR-MS with IAT ranging from 0.08 to $0.64 \mathrm{~s}$. The obtained mass spectra are shown in Figure 4. If the third series of peaks ("*” denoted in Figure 4B) are caused by space-charge frequency shifts of the first series of ions in NOM [for example, $\mathrm{m} / z$ at 399.01469, 399.05108, and 399.08746 are separately caused by "subtle shifts" of $m / z$ at 399.02052, 399.05691, and 399.09329 (the space-charge frequency shifts value is about $-6 \mathrm{mDa})]$, then the detected $m / z$ of PFHxS at 398.93655 (as shown in Figure 4A) would also shift subtly to $m / z$ about 398.93055 when IAT is extended to $0.64 \mathrm{~s}$. However, in our experiment, the results show the detected $m / z$ of PFHxS is 398.93663 (as shown in Figure 4B) when IAT is extended to $0.64 \mathrm{~s}$. This result could demonstrate that the third series of molecules are not caused by spacecharge frequency shifts of the first series of ions.

Since the above two possible pathways cannot explain the results, we believe that the third pathway seems more reasonable. A lot of evidence was also observed. First, the proposed molecular formulas of each series of peaks at nominal $\mathrm{m} / z 395$ are listed in Table 1 . It shows that the molecular formulas of the first series of peaks (“ $\odot$ ” denoted) contain carbon, oxygen, and hydrogen elements ranging from $\mathrm{C} 16$ to $\mathrm{C} 20, \mathrm{O} 8$ to $\mathrm{O} 12$, and $\mathrm{H} 11$ to $\mathrm{H} 27$, whereas the elemental contents vary from $\mathrm{C} 19$ to $\mathrm{C} 25, \mathrm{O} 4$ to $\mathrm{O} 10$, and $\mathrm{H} 7$ to $\mathrm{H} 31$ for those of the second series of peaks (" $\Delta$ " denoted) and C23 to $\mathrm{C} 27, \mathrm{O} 3$ to $\mathrm{O} 7$, and $\mathrm{H} 7$ to $\mathrm{H} 23$ for those of the third series of peaks (“*” denoted). These results suggest that the third series of molecules are the carbon-rich and oxygen-deficient compounds, whereas the first and the second series of molecules are the oxygen-rich and carbon-deficient (as compared with the third series of molecules) compounds. We infer that the third series of molecules may belong to weak polar or nonpolar constituents of NOM because of their high carbon and low oxygen contents. Therefore, in the ESI process, these series of molecules have so low ionization efficiency that they can only be observed with an extension of the IAT. The first and the second series of molecules may belong to polar 
Table 1. $\mathrm{CnHmOq}$ Identified by ESI-FTICR-MS with Different IAT $^{a}$

\begin{tabular}{ccccccc} 
& & & \multicolumn{5}{c}{ IAT $(\mathrm{s})$} \\
\cline { 5 - 7 } series & $m / z$ & ion formula & 0.08 & 0.64 & 1.0 & 2.0 \\
$\odot$ & 395.02560 & $\mathrm{C}_{16} \mathrm{H}_{11} \mathrm{O}_{12}$ & $\sqrt{ }$ & $\sqrt{ }$ & $\times$ & $\times$ \\
$\odot$ & 395.06200 & $\mathrm{C}_{17} \mathrm{H}_{15} \mathrm{O}_{11}$ & $\sqrt{ }$ & $\sqrt{ }$ & $\times$ & $\times$ \\
$\odot$ & 395.09836 & $\mathrm{C}_{18} \mathrm{H}_{19} \mathrm{O}_{10}$ & $\sqrt{ }$ & $\sqrt{ }$ & $\sqrt{ }$ & $\times$ \\
$\odot$ & 395.13476 & $\mathrm{C}_{19} \mathrm{H}_{23} \mathrm{O}_{9}$ & $\sqrt{ }$ & $\sqrt{ }$ & $\sqrt{ }$ & $\sqrt{ }$ \\
$\odot$ & 395.17114 & $\mathrm{C}_{20} \mathrm{H}_{27} \mathrm{O}_{8}$ & $\sqrt{ }$ & $\sqrt{ }$ & $\times$ & $\times$ \\
$\Delta$ & 395.00441 & $\mathrm{C}_{19} \mathrm{H}_{7} \mathrm{O}_{10}$ & $\sqrt{ }$ & $\sqrt{ }$ & $\sqrt{ }$ & $\sqrt{ }$ \\
$\Delta$ & 395.04083 & $\mathrm{C}_{20} \mathrm{H}_{11} \mathrm{O}_{9}$ & $\sqrt{ }$ & $\sqrt{ }$ & $\sqrt{ }$ & $\sqrt{ }$ \\
$\Delta$ & 395.07723 & $\mathrm{C}_{21} \mathrm{H}_{15} \mathrm{O}_{8}$ & $\sqrt{ }$ & $\sqrt{ }$ & $\sqrt{ }$ & $\sqrt{ }$ \\
$\Delta$ & 395.11361 & $\mathrm{C}_{22} \mathrm{H}_{19} \mathrm{O}_{7}$ & $\sqrt{ }$ & $\sqrt{ }$ & $\sqrt{ }$ & $\sqrt{ }$ \\
$\Delta$ & 395.14998 & $\mathrm{C}_{23} \mathrm{H}_{23} \mathrm{O}_{6}$ & $\times$ & $\sqrt{ }$ & $\sqrt{ }$ & $\sqrt{ }$ \\
$\Delta$ & 395.18636 & $\mathrm{C}_{24} \mathrm{H}_{27} \mathrm{O}_{5}$ & $\times$ & $\sqrt{ }$ & $\sqrt{ }$ & $\sqrt{ }$ \\
$\Delta$ & 395.22274 & $\mathrm{C}_{25} \mathrm{H}_{31} \mathrm{O}_{4}$ & $\times$ & $\sqrt{ }$ & $\sqrt{ }$ & $\sqrt{ }$ \\
$*$ & 395.01971 & $\mathrm{C}_{23} \mathrm{H}_{7} \mathrm{O}_{7}$ & $\times$ & $\sqrt{ }$ & $\sqrt{ }$ & $\sqrt{ }$ \\
$*$ & 395.05611 & $\mathrm{C}_{24} \mathrm{H}_{11} \mathrm{O}_{6}$ & $\times$ & $\sqrt{ }$ & $\sqrt{ }$ & $\sqrt{ }$ \\
$*$ & 395.09248 & $\mathrm{C}_{25} \mathrm{H}_{15} \mathrm{O}_{5}$ & $\times$ & $\sqrt{ }$ & $\sqrt{ }$ & $\sqrt{ }$ \\
$*$ & 395.12886 & $\mathrm{C}_{26} \mathrm{H}_{19} \mathrm{O}_{4}$ & $\times$ & $\sqrt{ }$ & $\sqrt{ }$ & $\sqrt{ }$ \\
$*$ & 395.16523 & $\mathrm{C}_{27} \mathrm{H}_{23} \mathrm{O}_{3}$ & $\times$ & $\sqrt{ }$ & $\sqrt{ }$ & $\sqrt{ }$
\end{tabular}

${ }^{a}$ Note: “ $\odot$ ", “ $\Delta$ ", and “*” denoted different series of peaks; " $\sqrt{ }$ "denoted being capable of detection; " $X$ "denoted being incapable of detection. constituents of NOM with high ionization efficiency, so they can be easily detected by FTICR-MS using a short IAT.

Normally, trace bases in the sample solution are able to increase the ionization efficiency of compound in the negative ESI mode. If the third series of molecules belong to weak polar or nonpolar constituents of NOM, although having low ionization efficiency, these ions may also be detected by adding trace bases in aqueous solution. Therefore, in our experiment, 3 $\mu \mathrm{L}$ of $28 \%$ ammonia-water was added to $1 \mathrm{~mL}$ of $\mathrm{NOM}$ solutions $\left(0.1 \mathrm{mg} \mathrm{mL}^{-1}\right)$; then, the final solution $(\mathrm{pH}=8.0)$ was vortexed and detected by FTICR-MS. The obtained mass spectra are shown in Figure 5. It is remarkable to show that the third series of peaks ("*" denoted in Figure 5C) are observed with a short IAT $(0.08 \mathrm{~s})$ when ammonia-water was added. This result shows direct evidence for the third pathway.

Additionally, if the third series of molecules really exist in NOM but are not detected, mainly due to the low ionization efficiency or interference by other constituents of NOM, these molecules may be detected by a method which is the so-called Continuous Accumulation of Selected Ions (CASI). With this method, these molecules could be isolated by a quadrupole mass filter and then accumulated in the collision cell for a long time. After continuous storage in the collision cell, the number of these isolated ions could be increased, and these ions could subsequently be transferred to the ICR cell for detection with higher intensities. In order to demonstrate this hypothesis, masses with nominal $\mathrm{m} / z$ at 395 were isolated with an isolation

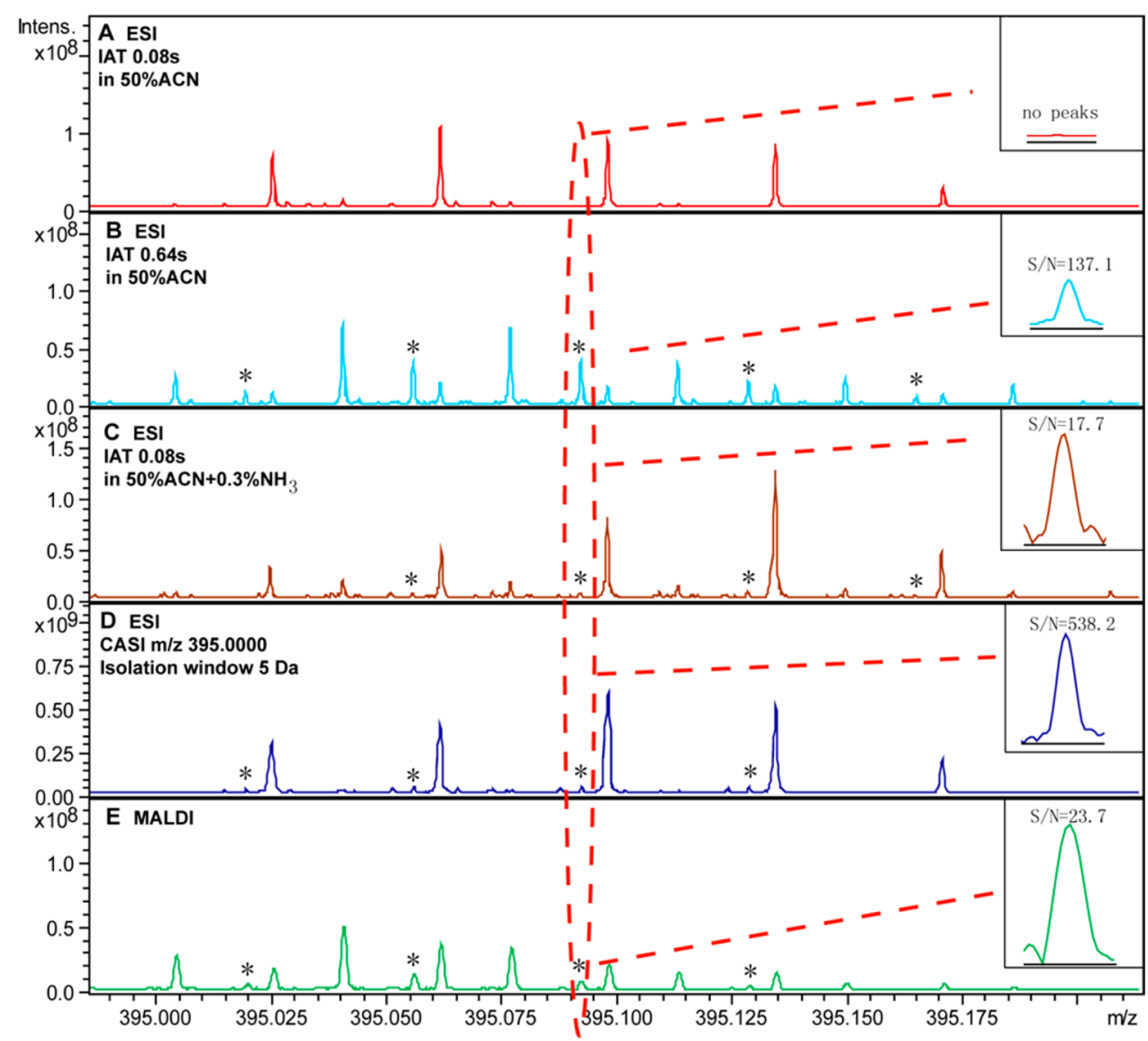

Figure 5. FTICR mass spectra of NOM extended in scale at nominal $\mathrm{m} / z 395$; (A) obtained by ESI with IAT at $0.08 \mathrm{~s}$, NOM in $50 \%$ ACN aqueous solution; (B) obtained by ESI with IAT at $0.64 \mathrm{~s}$, NOM in 50\% ACN aqueous solution; (C) obtained by ESI with IAT at $0.08 \mathrm{~s}$, NOM in $50 \%$ ACN and $0.3 \% \mathrm{NH}_{3}$ aqueous solution; (D) obtained by CASI method, NOM in 50\% ACN aqueous solution; (E) obtained by MALDI; “*” denoted the third series of peaks; inset figures show $\mathrm{S} / \mathrm{N}$ of one of the third series peaks. 

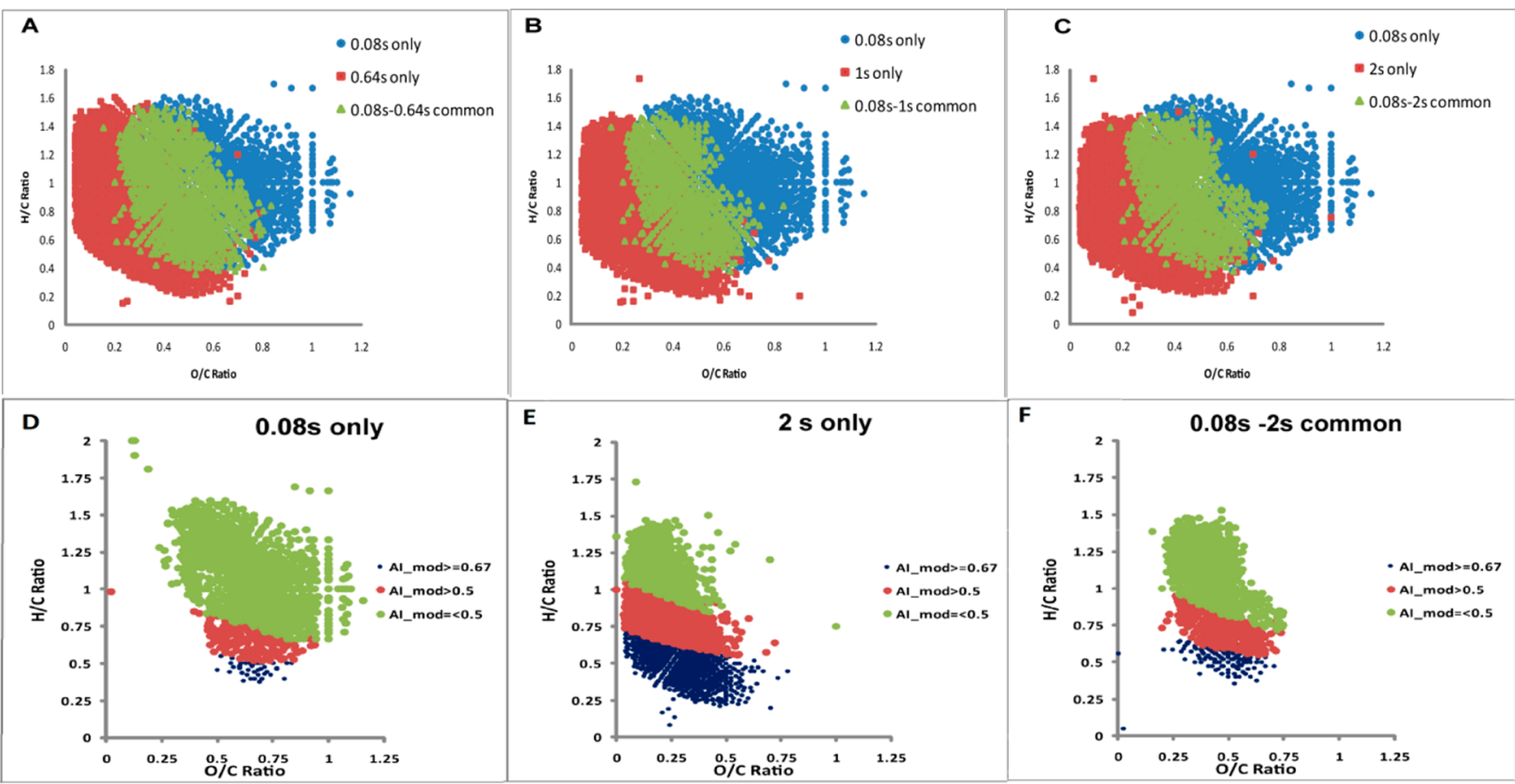

Figure 6. Van Krevelen diagrams for molecular formulas observed in NOM with different IAT; (A) IAT at 0.08 and $0.64 \mathrm{~s}$; (B) IAT at 0.08 and $1 \mathrm{~s}$; (C) IAT at 0.08 and $2 \mathrm{~s}$; (D) only observed with IAT at $0.08 \mathrm{~s}$; (E) only observed with IAT at $2 \mathrm{~s}$; (F) commonly observed with IAT at 0.08 and $2 \mathrm{~s}$. Aromatic and condensed aromatic structures can be identified with threshold criteria of $\mathrm{AI}_{\text {mod }}>0.5$ (red dots) and $\mathrm{AI}_{\text {mod }} \geq 0.67$ (blue dots) in (D-F).

window of 5 mass units and, then, were accumulated in the collision cell for $10 \mathrm{~s}$ and, subsequently, were transferred into the ICR cell for detection. The obtained mass spectrum is shown in Figure 5D. Compared with mass spectra obtained with IAT at 0.08 and $0.64 \mathrm{~s}$, it is obvious that the third series ("*) denoted in Figure 5) of peaks could also be observed by this CASI method. This result further demonstrated that the third series of molecules originally exist in the NOM sample.

Furthermore, the mass spectra obtained with different IAT by ESI-FTICR-MS were also compared with our published results $^{37}$ which were obtained by MALDI-FTICR-MS. It was surprising to show that the third series of molecules could also be easily detected by MALDI-FTICR-MS (as shown in Figure $5 \mathrm{E})$. This is additional evidence to demonstrate the original existence of the third series of molecules in NOM.

On the basis of the above results, we believe that IAT has great effect on the molecular characterization of NOM by FTICR-MS. First, extending IAT could influence the MS intensities of some molecules in NOM (such as the first series of peaks and the second series of peaks in Figure 2). Second, some molecules (such as the third series of peaks in Figure 2), which cannot be observed by FTICR-MS with a short IAT ( such as $0.08 \mathrm{~s}$ ), are able to be remarkably detected with a long IAT (such as $0.0 .64 \mathrm{~s}$ or more). The possible mechanism for the generation of these results is proposed as follows: the polar molecules of NOM with high $\mathrm{O} / \mathrm{C}$ ratio have high ionization efficiency so that short IAT could result in accumulation of enough of these ions for detection. However, by extending IAT, these molecules may become unstable in the collision cell due to their special properties or the collision with neutral gas, which causes their MS intensities to decrease or disappear. On the other hand, the molecules only detected with an extension of IAT may be relatively stable compounds with low polarity which leads to low ionization efficiency. Extending IAT results in an increase in the number of these molecular ions accumulated in the collision cell. Although the stable ions also have collisions with each other or neutral gas, the number of these ions may still keep increasing in the collision cell with an extension of IAT, which is beneficial for the final detection.

On the basis of these results, we propose a novel strategy of combining MS data of NOM obtained by FTICR-MS with different IAT in order to obtain more molecular information on NOM. The obtained mass spectral data of NOM with different IAT are automatically processed with formula assigned software, and different parameters are calculated for visual graphic comparison of these types of mass spectral data. It is shown that a total of $2733 \mathrm{CHO}$-molecular formulas are assigned with a short IAT $(0.08 \mathrm{~s})$; however, by extending the IAT range from 0.64 to $2 \mathrm{~s}$, about 2000 new CHO-molecular formulas are further observed with each extension of the IAT. Compared with the formulas obtained with IAT at $0.08 \mathrm{~s}$, the number of unique formulas obtained by extending IAT, respectively, at $0.64,1$, and $2 \mathrm{~s}$, is separately $1982(42 \%)$, 2157 (44\%), and 2146 (44\%). That means more than 4715 CHO-molecular formulas would be obtained if the data generated with IAT at $0.08 \mathrm{~s}$ is combined with that obtained with IAT at $0.64 \mathrm{~s}$ or more. Therefore, in order to extract more molecular information on NOM, a NOM sample should be detected with different IAT, respectively, and then, all of the results with different IAT should be combined.

Moreover, to further compare the whole mass range of detected ions using different IAT, Van Krevelen diagrams are constructed for each formula (as shown in Figure 6A-C). A notable feature of selective detection of NOM molecules with different IAT is visually observed. In general, most of the molecules only detected with IAT at $0.08 \mathrm{~s}$ are those with higher $\mathrm{O} / \mathrm{C}$ ratio $(\mathrm{O} / \mathrm{C}$ ratio $>0.5)$, whereas, for the molecules only observed with long IAT ranging from 0.64 to $2 \mathrm{~s}$, a 
majority of them are the molecules of relatively lower $\mathrm{O} / \mathrm{C}$ ratio $(\mathrm{O} / \mathrm{C}$ ratio $<0.6)$. Most of the molecules with $\mathrm{O} / \mathrm{C}$ ratio ranging from 0.4 to 0.7 could always be observed with IAT ranging from 0.08 to $2 \mathrm{~s}$. This result further reveals that carbonrich and oxygen-deficient constituents of NOM could be selectively detected by ESI-FTICR-MS with an extension of IAT, but for the carbon-deficient and oxygen-rich constituents of NOM, short IAT should be set for their detection.

To estimate the aromatic and condensed aromatic structures of NOM molecules detected with different IAT, a modified aromaticity index ( $\mathrm{AI}_{\mathrm{mod}}$ ) is calculated from the formulas according to previous works. ${ }^{37}$ Aromatic and condensed aromatic structures can be identified with threshold criteria of $\mathrm{AI}_{\text {mod }}>0.5$ and $\mathrm{AI}_{\text {mod }} \geq 0.67$ (as shown in Figure 6D-F). It is obvious that about $70 \%$ of the molecules only detected with an extension of IAT to $2 \mathrm{~s}$ contain aromatic structures, including a large proportion of condensed aromatic structures (about 40\%). Furthermore, nearly all of these molecules have $\mathrm{O} / \mathrm{C}$ ratios lower than 0.6 (as shown in Figure 6E). However, for the molecules only detected with short IAT at $0.08 \mathrm{~s}$ (as shown in Figure 6D), only about $15 \%$ of them involve aromatic structures, and of those, only a small proportion of condensed aromatic structures (about 6\%) are included. Meanwhile, the majority of them have higher $\mathrm{O} / \mathrm{C}$ ratios $(1.2>\mathrm{O} / \mathrm{C}$ ratios $>$ $0.4)$. These results indicate that a large part of the aromatic and condensed aromatic molecules with low O/C ratio in NOM could be detected by ESI-FTICR-MS with an extension of IAT. We speculate that aromatic structures and lower $\mathrm{O} / \mathrm{C}$ ratio may lead the compounds to have lower polarity, which causes them low ionization efficiency in the ESI ionization process.

\section{CONCLUSIONS}

As a key parameter of FTICR-MS for complex mixture detection, the great effect of IAT on the molecular characterization of NOM by FTICR-MS is first reported. Most of polar molecules with high $\mathrm{O} / \mathrm{C}$ ratio $(\mathrm{O} / \mathrm{C}$ ratio $>0.5)$ could be easily detected by FTICR-MS with a short IAT. However, extending IAT could lead to the ion intensities of these molecules to decrease or even disappear. Meanwhile, a large number of unsaturated and aromatic molecules with low $\mathrm{O} / \mathrm{C}$ ratio $(\mathrm{O} / \mathrm{C}$ ratio $<0.6)$ and low polarity, which originally existed in NOM but cannot be detected with a short IAT, are remarkably detected by extending IAT. The possible reasons for these results are that the polar molecules with high $\mathrm{O} / \mathrm{C}$ ratio have high ionization efficiency so that a short IAT could result in accumulation of enough of these ions for detection; however, by extending IAT, these molecules become unstable in the collision cell due to their special properties or collision with neutral gas. All of this causes their MS intensities to decrease or disappear. On the other hand, the molecules only detected by the extension of the IAT may be some chemically stable compounds with low polarity and low ionization efficiency. Extending IAT leads to an increase of the number of these molecular ions accumulated in the collision cell. Although such ions may also collide with each other or neutral gas, they may still exist in the collision cell due to the stable properties. All of these results indicated that IAT is an important parameter of FTICR-MS for NOM detection. In order to obtain reliable and repeatable results during detection of NOM, IAT should be paid much attention. Moreover, by combining mass spectrometric data of NOM obtained with different IAT, more than $4715 \mathrm{CHO}$-molecular formulas would be assigned, where about 2000 more formulas were obtained in comparison with using a short IAT (2733 CHO-molecular formulas identified) solely. We believe that the strategy of combining mass spectrometric data of NOM obtained with different IAT could be used as a novel method to achieve more molecular information on NOM.

\section{AUTHOR INFORMATION}

\section{Corresponding Author}

*Tel: +86-10-62849729. Fax: +86-10-62849729. E-mail: yhkang@rcees.ac.cn.

ORCID

Dong Cao: 0000-0001-8793-4401

Notes

The authors declare no competing financial interest.

\section{ACKNOWLEDGMENTS}

The authors are thankful to Dr. Keyu Zhou, Dr. Qing Zhang, and Dr. Juan Wei at Bruker Daltonik Company for their helpful discussions and constructive suggestions. We also thank the two anonymous reviewers for their helpful and professional comments which were valuable to improve the quality of our manuscript. This work was supported by the National Basic Research Program of China (973 program, 2014CB441102) and the National Natural Science Foundation of China (Nos. 21537004, 21477140, 21007079).

\section{REFERENCES}

(1) Hedges, J. I. Mar. Chem. 1992, 39, 67-93.

(2) Klotz, D.; Lazik, D. Isot. Environ. Health Stud. 1995, 31, 61-75.

(3) Wolf, M.; Teichmann, G.; Hoque, E.; Szymczak, W.; Schimmack, W. Fresenius' J. Anal. Chem. 1999, 363, 596-599.

(4) Lyon, B. A.; Milsk, R. Y.; DeAngelo, A. B.; Simmons, J. E.; Moyer, M. P.; Weinberg, H. S. Environ. Sci. Technol. 2014, 48, 6743-6753.

(5) Lavonen, E. E.; Gonsior, M.; Tranvik, L. J.; Schmitt-Kopplin, P.; Köhler, S. J. Environ. Sci. Technol. 2013, 47, 2264-2271.

(6) Stevenson, F. J. Humus Chemistry: Genesis, Composition, Reactions, 2nd ed.; John Wiley \& Sons, Ltd: New York, 1994.

(7) Swift, R. S. Soil Sci. 1999, 164, 790-802.

(8) Simpson, A. J. Magn. Reson. Chem. 2002, 40, S72-S82.

(9) von Wandruszka, R. Soil Sci. 1998, 163, 921-930.

(10) Maurice, P. A.; Namjesnik-Dejanovic, K. Environ. Sci. Technol. 1999, 33, 1538-1541.

(11) Namjesnik-Dejanovic, K.; Maurice, P. A. Geochim. Cosmochim. Acta 2001, 65, 1047-1057.

(12) Leenheer, J. A.; Rostad, C. E.; Gates, P. M.; Furlong, E. T.; Ferrer, I. Anal. Chem. 2001, 73, 1461-1471.

(13) Piccolo, A.; Spiteller, M. Anal. Bioanal. Chem. 2003, 377, 10471059.

(14) Brown, T. L.; Rice, J. A. Org. Geochem. 2000, 31, 627-634.

(15) Simpson, A. J.; Kingery, W. L.; Hayes, M. H. B.; Spraul, M.; Humpfer, E.; Dvortsak, P.; Kerssebaum, R.; Godejohann, M.; Hofmann, M. Naturwissenschaften 2002, 89, 84-88.

(16) Piccolo, A. Soil Sci. 2001, 166, 810-832.

(17) Sutton, R.; Sposito, G. Environ. Sci. Technol. 2005, 39, 90099015.

(18) Minor, E. C.; Swenson, M. M.; Mattson, B. M.; Oyler, A. R. Environ. Sci.: Processes Impacts 2014, 16, 2064-2079.

(19) Stenson, A. C.; Marshall, A. G.; Cooper, W. T. Anal. Chem. 2003, 75, 1275-1284.

(20) Hertkorn, N.; Frommberger, M.; Witt, M.; Koch, B. P.; SchmittKopplin, P.; Perdue, E. M. Anal. Chem. 2008, 80, 8908-8919.

(21) Riedel, T.; Biester, H.; Dittmar, T. Environ. Sci. Technol. 2012, 46, 4419-4426.

(22) Sleighter, R. L.; Hatcher, P. G. Fourier Transforms - Approach to Scientific Principles 2011, 295-320. 
(23) Lv, J. T.; Zhang, S. Z.; Wang, S. S.; Luo, L.; Cao, D.; Christie, P. Environ. Sci. Technol. 2016, 50, 2328-2336.

(24) Koch, B. P.; Dittmar, T. Rapid Commun. Mass Spectrom. 2006, 20, 926-932.

(25) Kim, S.; Kramer, R. W.; Hatcher, P. G. Anal. Chem. 2003, 75, 5336-5344.

(26) Hughey, C. A.; Hendrickson, C. L.; Rodgers, R. P.; Marshall, A. G.; Qian, K. Anal. Chem. 2001, 73, 4676-4681.

(27) Wu, F. C.; Evans, R. D.; Dillon, P. J. Anal. Chim. Acta 2002, 464, $47-55$.

(28) Wu, F. C.; Evans, R. D.; Dillon, P. J. Environ. Sci. Technol. 2003, 37, 3687-3693.

(29) Reemtsma, T.; These, A.; Springer, A.; Linscheid, M. Water Res. 2008, 42, 63-72.

(30) Stenson, A. C. Environ. Sci. Technol. 2008, 42, 2060-2065.

(31) Tfaily, M. M.; Hodgkins, S.; Podgorski, D. C.; Chanton, J. P.; Cooper, W. T. Anal. Bioanal. Chem. 2012, 404, 447-457.

(32) Sleighter, R. L.; Caricasole, P.; Richards, K. M.; Hanson, T.; Hatcher, P. G. Chem. Biol. Technol. Agric. 2015, 2, 9-28.

(33) Koch, B. P.; Ludwichowski, K. U.; Kattner, G.; Dittmar, T.; Witt, M. Mar. Chem. 2008, 111, 233-241.

(34) Tfaily, M. M.; Chu, R. K.; Tolić, N.; Roscioli, K. M.; Anderton, C. R.; Paš a-Tolić, L.; Robinson, E. W.; Hess, N. J. Anal. Chem. 2015, $87,5206-5215$.

(35) Mopper, K.; Stubbins, A.; Ritchie, J. D.; Bialk, H. M.; Hatcher, P. G. Chem. Rev. 2007, 107, 419-442.

(36) D’Andrilli, J.; Dittmar, T.; Koch, B. P.; Purcell, J. M.; Marshall, A. G.; Cooper, W. T. Rapid Commun. Mass Spectrom. 2010, 24, 643650.

(37) Cao, D.; Huang, H. G.; Hu, M.; Cui, L.; Geng, F. L.; Rao, Z. Y.; Niu, H. Y.; Cai, Y. Q.; Kang, Y. H. Anal. Chim. Acta 2015, 866, 48-58.

(38) Kunenkov, E. V.; Kononikhin, A. S.; Perminova, I. V.; Hertkorn, N.; Gaspar, A.; Schmitt-Kopplin, Ph.; Popov, I. A.; Garmash, A. V.; Nikolaev, E. N. Anal. Chem. 2009, 81, 10106-10115.

(39) Brown, T. L.; Rice, J. A. Anal. Chem. 2000, 72, 384-390.

(40) Belov, M. E.; Nikolaev, E. N.; Anderson, G. A.; Udseth, H. R.; Conrads, T. P.; Veenstra, T. D.; Masselon, C. D.; Gorshkov, M. V.; Smith, R. D. Anal. Chem. 2001, 73, 253-261.

(41) Belov, M. E.; Nikolaev, E. N.; Harkewicz, R.; Masselon, C. D.; Alving, K.; Smith, R. D. Int. J. Mass Spectrom. 2001, 208, 205-225.

(42) Sannes-Lowery, K.; Griffey, R. H.; Kruppa, G. H.; Speir, J. P.; Hofstadler, S. A. Rapid Commun. Mass Spectrom. 1998, 12, 19571961.

(43) Da Campo, R.; Barrow, M. P.; Shepherd, A. G.; Salisbury, M.; Derrick, P. J. Energy Fuels 2009, 23, 5544-5549.

(44) Maziarz, E. P., III; Baker, G. A.; Lorenz, S. A.; Wood, T. D. J. Am. Soc. Mass Spectrom. 1999, 10, 1298-1304.

(45) Witt, M.; Fuchser, J.; Koch, B. P. Anal. Chem. 2009, 81, 26882694. 